\title{
The Ethical Dimension of the German Federal Constitutional Court's Decision Concerning Data Retention
}

\author{
Christoph Luetge*
}

Technical University of Braunschweig, Bienroder Weg 80, D-38106 Braunschweig, Germany

\begin{abstract}
In March 2008, the German Federal Constitutional Court (GFCC) has passed an important, even though preliminary, decision concerning data retention. The GFCC's decision accepts the storage of data, but greatly restricts their use to serious offenses like murder and organized crime.

From an ethical point of view, it is particularly interesting to look at the justification given by the GFCC, which relies heavily on the argument that the "impartiality" (Unbefangenheit) of communication will be thoroughly damaged if feelings of being watched spread in a society. This argument is examined in view of two contrasting theoretical approaches: Discourse ethics and evolutionary contractarian theory.
\end{abstract}

\section{INTRODUCTION}

In March 2008, the German Federal Constitutional Court (GFCC) has passed an important decision concerning data retention. This decision is a preliminary one, but it can reasonably be anticipated that the court's final decision, expected for 2009 or 2010, will not be much different. It is an exceptionally rare occurrence for the GFCC to stop a law in a preliminary decision. And as the general subject of data retention is a very important one internationally, it is worthwhile to look at the major arguments used in this case. There are ethical assumptions behind those arguments and I will try for a reconstruction of these.

First, I will describe the general legal setting and framework for the German Law on Data Retention, which goes back to a European Union directive (sections 2 and 3). I will then deal with the court's decision in section 4 , looking at the arguments in detail in section 5. Sections 6 and 7 are concerned with the theoretical background of the argument. While section 6 sketches and eventually criticizes a Habermasian discourse ethics background, section 7 tries to find a better suited theoretical background for the GFCC's argument in evolutionary contractarian theory. The paper ends with a conclusion.

\section{THE 2006 EUROPEAN UNION DIRECTIVE ON DATA RETENTION}

Following terrorist attacks like those of September 2001 in New York and March 2004 in Madrid, many voices within the European Union (EU) saw a need for greater possibilities of communication data retention, concerning cell phones, internet usage, emails, fax and SMS. There was a long discussion about whether an EU directive could be passed by the European Council alone or whether it required the consent of the European Parliament. Eventually, in

*Address correspondence to this author at the Technical University of Braunschweig, Bienroder Weg 80, D-38106 Braunschweig, Germany;

Tel: +495313918616; Fax: +495313918619; E-mail: Christoph@Luetge.de
December 2005, the European Parliament voted for the directive with a majority of 378 (of 605 seats).

The EU Council was however not unanimous with regard to the directive. Especially Ireland and Slovakia were (and still are) categorically opposed to it. So the usual unanimous vote could not be reached. The EU Council therefore declared the directive not a rule aiming at better criminal prosecution, but a new regulation for competition in the communication sector in the EU member states. Such regulations do not require unanimous consent of all states. Consequently, in February 2006, the EU Council passed a majority vote for the new directive, which now bears the name "EU Directive 2006/24/EG".

Ireland has already gone to the European Court of Justice, claiming that the new directive is in fact not just a rule regulating competition, but a rule for criminal prosecution and therefore could only have been passed with unanimous consent of all EU member states. As of June 2008, the European Court's decision is however still due.

\section{THE 2007 GERMAN LAW ON DATA RETENTION}

There had already been several attempts in Germany to pass a law on data retention during the last 10-15 years. In 1997, the Kohl administration rejected an initiative put forward by the Bundesrat, the second chamber of the German Parliament. The federal government itself regarded a wideranging collection of data unconstitutional. Also, in the aftermath of September 2001, several more attempts had been launched, but none of them was successful - until the EU took action.

After the EU Directive 2006/24/EG had been passed, the member states were required to put it into national law until September 2007. In April 2007, the German Government presented a new law on undercover criminal prosecution, which incorporated major parts of the EU directive. This law was passed by the German Parliament in November 2007 and became effective by January $1^{\text {st }} 2008$. 
The new law bears the name "Gesetz zur Neuregelung der Telekommunikationsüberwachung und anderer verdeckter Ermittlungsmaßnahmen sowie zur Umsetzung der Richtlinie 2006/24/EG" (Law concerning a new regulation of telecommunication surveillance and other undercover criminal prosecution and for implementing the directive 2006/24/EG). I will henceforth call it simply the German Law on Data Retention (GLDR).

This law basically requires all telecommunication providers to store their connections data for at least six and for a maximum of seven months. These data include in particular:

- In the case of phone, cell phone and internet phone communication: the telephone numbers (or IP addresses) of the calling and the called party, start and end time of the connection, the use of special communication services (like conference calls) and the use of radio cells, thus allowing for geographically locating communicating parties.

- In the case of email communication: the time and IP addresses of sender and receiver, both when a message is sent and when it is collected from a mailbox.

- In the case of Internet usage: IP addresses of the users, start and end time of the connection.

The GLDR does however not allow the storage of contents of communication.

The GLDR originally allowed for these data to be used for a number of purposes:

1) For all kinds of criminal prosecution.

2) For the defense against significant dangers to public security.

3) For the (non-specified) use of the German intelligence agencies.

4) For getting information about telecommunication users in general ( $\$ 113 \mathrm{TKG}$, telecommunication law).

While the GLDR allowed only state authorities to make use of the data, private parties could however have filed a case of any kind that concerns offenses that were committed with the aid of telecommunication, and then have looked at the inquiry files. In particular, this would have included copyright infringements in file sharing networks.

The purposes for which the GLDR could have been used were practically all-encompassing. The vast majority of offenses are committed making at least a phone call - or sending an email. Moreover, even the smallest offenses like parking tickets could have led to telecommunication surveillance according to this law. Thus the new law would have set very low standards for the use of private communication data.

\section{THE GFCC'S DECISION}

In December 2007, a constitutional complaint against the GLDR was filed. For the first time since the Federal Republic exists, a constitutional complaint was backed by more than 30,000 people. As this number was too large to verify all the mandates, eventually eight complaints were filed.

On 03/19/2008, the GFCC decided that while the practice of data retention was not to be stopped completely, the use of the data collected was severely restricted [1]:
1) The data may only be given to criminal prosecution authorities, not to any other parties like private companies.

2) The data may only be used with permission by a judge, not just by decision of any local police authority.

3) The most important restriction is that the data may only be used for the prosecution of severe offenses. There is a list which states what offenses are considered as severe ones in this regard - and the GFCC has made it clear that it believes even this list to be too extensive. Included in this list are murder and homicide, but also tax fraud, economic subsidy fraud and falsification of documents. The list is thus quite extensive, but it rules out the use for all kinds of criminal prosecution, or simply getting data about users for a company's purpose, or the totally unspecified use for virtually unlimited intelligence purposes.

The decision is a preliminary one ("Eilentscheidung"), which is highly unusual for the GFCC. There have been only very few cases where the GFCC has preliminary stopped a law or at least major parts of it. And the judges have explicitly stated that there are very tight conditions for such a decision. Moreover, in the case of the GLDR, these conditions are themselves even more strict because the EU directive on data retention requires EU member states to have some national legislation in this regard.

Nevertheless, the judges of the GFCC decided it necessary to stop the full impact of this law. This preliminary decision remains effective until a final decision will be issued which is expected for 2009 or 2010.

\section{THE GFCC'S ARGUMENTS}

In its decision, the GFCC has made use of mainly three arguments which are however intertwined: There is a general danger to the individual personality, there is the specific danger that the impartiality of communication ("Unbefangenheit der Kommunikation") gets lost by allowing for farreaching data surveillance, and there is a danger that completely uninvolved persons will be put under surveillance without sufficient suspicious facts. I will discuss these arguments in turn, starting with the last one.

\subsection{The Argument about the Danger to Uninvolved Per- sons}

This argument is a rather common one. The GFCC believes that the information retrieval is a fundamental and irreversible intrusion into basic rights, especially as it enables authorities to monitor communication behavior and social contacts not only of a suspect, but necessarily of other persons as well. The GFCC states that it is unavoidable that other people, who are completely unrelated to the offenses under investigation, are subject to the same measures as suspects.

\subsection{The Argument about the Danger to Personality}

The GFCC states that the GLDR poses a general threat to citizens' personality. Retaining data on a massive scale without giving specific reasons implies that nearly every citizen is affected. The GFCC regards this as a considerable 
threat to the right to privacy found in article 10 of the Basic Constitutional Law ("Grundgesetz").

\subsection{The Argument about the Impartiality of Communi- cation}

The GFCC, however, goes on to specify what the danger to personality consists in. The court argues that the massive data retention envisaged by the GLDR threatens to shatter both the impartiality of communication ("Unbefangenheit des Kommunikationsaustauschs") as well as the general confidence in the inaccessibility of telecommunication facilities and data ("Vertrauen in den Schutz der Unzugänglichkeit der Telekommunikationsanlagen insgesamt").

These are two separate parts of the argument. With regard to the first one, "impartiality" is however only an imperfect translation of "Unbefangenheit", which rather means speaking freely and without a feeling of being spied on.

The second part of the argument assumes that there is a general feeling among citizens that their telecommunication data are inaccessible. This is quite a strong assumption - and it could be argued that this feeling is already gone to a large part. But still, the GFCC can be interpreted as aiming at preventing these feelings to erode even further.

\section{COMMUNICATION IN A DISCOURSE ETHICS PERSPECTIVE}

On what theoretical grounds should the impartiality of communication be such an important thing? One answer is given in the discourse ethics of J. Habermas. Habermas regards impartial communication as a necessity for societies. A society can, according to Habermas, remain stable only if citizens communicate without continually being motivated by self-interest alone, by trying to secure their interests and needs, by trying to maximize their utility. They need to be able to discuss, criticize and argue without explicit, systematic reference to their own interests.

Habermas puts it like this: The participants of a discourse must allow their behavior - at least partially - to be motivated by a rational motivation [2-4]. Only through rational motivation can they overcome strategic action and reach communicative action. This is Habermas' central antagonism: While strategic action is affected by incentives and sanctions, communicative action is led by rational motivation. Someone who acts from rational motivation is led by some kind of motivation beyond self-interest.

The question is whether rational motivation can remain stable in view of opposing incentives. Habermas argues that no actor can escape the "lifeworld" ("Lebenswelt"), which according to Habermas - is formed by cultural tradition and socialization which in turn work through rational motivation. If an actor tried to escape, he would end in "schizophrenia and suicide" ([3], p. 112; my translation). However, this reconstruction of the lifeworld is doubtful. There are alternative, and less harmonious, reconstructions of the lifeworld possible. One major example is the game-theoretic approach that reconstructs all human interactions as being 'riddled' with dilemma situations like the prisoners' dilemma (PD). These situations can be either manifest (as in open market interactions with competition being obvious) or hidden. Hid- den PD situations that have been overcome are exemplified prominently in many institutions like laws and jurisdiction: These institutions come into effect as a consequence of the social contract, which enables the actors to escape from the natural state, i.e., a PD situation. And approaches like Binmore's $[4,5]$ assign the PD a central role for ethics.

In a perspective that does not look beyond the surface, however, it looks as if the individuals which act according to these institutions have been moved by a rational motivation. The 'deeper' structures behind become visible - and it becomes clear that it is not just rational motivation, but rather (in this case, informal) incentives and possible sanctions that hold this social practice in place. This casts doubt on Habermas' claim to have found the only reconstruction of everyday practices.

\section{HOW THE GFCC'S THIRD ARGUMENT MIGHT BE RECONSTRUCTED}

Of course, communication is not impartial in the sense that we can be completely unbiased, free from external constraints and not under external pressure of any kind. This would be a much too far-reaching conclusion. I think, however, that the third argument does not rest solely on a discourse ethics basis, but can be made sense of in another perspective. Impartial communication does not have to be related to a "rational motivation", but can be reconstructed on a basis of pure self-interest:

It is to the advantage of all involved if people can communicate impartially. Or, more precisely: It is a loss of wellbeing for all involved if communication gets less impartial which does not require it to be totally impartial.

But less impartial communication might destroy empathy. This concept of empathy has been thoroughly analyzed in Ken Binmore's "Game Theory and the Social Contract":

Binmore has proposed an evolutionary contractarian approach which he calls "naturalistic", as it relies both on game-theoretic and on sociobiological concepts. A central demand of Binmore's naturalism is: No commitments! I will discuss this first and then elaborate on Binmore's concept of "empathetic preferences", which he sees as necessary for social stability. However, as I will try to show, these empathetic preferences are fundamentally different from the rational motivation discussed so far. For reconstructing the GFCC's decision, empathetic preferences are all that is needed. A resort to stronger concepts like rational motivation is unnecessary.

Binmore emphasizes that a naturalistic approach must abandon all authorities legitimated by metaphysics. According to him, the vast majority of contemporary approaches in political philosophy - among them, Rawls, Harsanyi, Gauthier and Nozick - give metaphysical justifications for rules and institutions. The common idea of these approaches is that actors can make commitments, i.e., binding unilateral promises ([5], p. 161) that ultimately cannot be revoked and therefore do not have to be enforced by sanctions.

The major problem in assuming the possibility of commitments is the construction of a plausible mechanism of enforcement (cf. [5], p. 162). It is difficult to commit oneself as well as convincing others that one has committed oneself. 
One possible solution is to provide (financial) 'hostages': For example, a company that has made a commitment to environmental protection may sign a contract in which they commit themselves to paying a fixed amount of money if the commitment is broken. And there are other, more subtle, mechanisms of securing commitments via reputation mechanisms.

Binmore, however, proposes a different concept: empathetic preferences. The intuitive idea behind this is that even a homo oeconomicus actor can adapt his actions better to that of other actors if he can predict their behavior. Binmore distinguishes sharply between a sympathetic and an empathetic preference:

An actor A reveals a sympathetic preference, if it can be deduced from his behavior that he puts himself into actor B's position and adopts B's preferences (cf. [5], p. 286). By contrast, actor A reveals an empathetic preference, if it can be deduced from his behavior that he puts himself into actor B's position without taking on B's preferences. In this case, A sticks to his own preferences. He can still compare his preferences to B's and evaluate or criticize the latter. To cite Binmore's example: "I would rather be Eve eating an apple than Adam wearing a fig leaf" ([5], p. 290).

Binmore argues that the ability to empathize, and not the ability to sympathize with others is what makes a human being. He speculates about the evolutionary history of this ability which may have been advantageous for coordinating behavior in hunter-gatherer societies (cf. [5], pp. 57 and 288ff.). And he distinguishes between three time horizons in which empathetic preferences play a role: short, medium, and long run.

In the short run, the personal preferences of an actor as well as her empathetic preferences are fixed, i.e., the actor empathizes in exactly the way her empathetic preferences prescribe and deliberates 'morally' in this way. Here, moral norms are conventions, which work as short cuts for long economic calculations. While morals do not play a role on the level of the social contract framework, they do influence the individuals' actions within this framework. Morals are functional in the short run (cf. [6], ch. 4.6.8). The GFCC's decision would certainly fall into this category.

In the long run, all preferences, personal and empathetic, are subject to change, as the actor adapts to new situations and new rules. Here, new social contracts are negotiated and existing ones modified. The personal and empathetic preferences adapt to these new situations. It is interesting to see that in the long run, all moral content erodes out of the preferences. Over longer periods time, the actors arrive - via 'moral' empathy - at the same result as if they had been bargaining straightaway all the time. Binmore makes it clear that - in the long run - morals serve long-run interests, and, more importantly, no moral norms can remain stable that are systematically opposed to incentives.

Finally, in the medium run, the personal preferences remain fixed while the empathetic ones may change. According to Binmore, evolution will bring the latter into "empathy equilibrium" ([5], p. 65), in which all actors have equal empathetic preferences. It is already in this situation - as in the long run - that all moral content erodes from the social contract framework. The actors end up with a result identical to a Nash bargaining equilibrium (cf. [7, 8]). However, this is at variance with the actors' own impression: Due to the semantics employed, they still think that they are guided by moral deliberation in the traditional sense. Binmore consequently regards the ability to empathize as - at least partially - genetically "hard-wired" ([5], p. 133). The difference between the long and medium run is that in the medium run, evolution has not had enough time to shape personal preferences and adapt them to new environments and situations.

By distinguishing between the three time horizons, Binmore defines the role of empathetic preferences in society: They are used for coordination, or more precisely: for reforming existing social contracts and consenting to new ones. They are used as a heuristic tool for finding directions in which new social contracts may develop. In this sense, Binmore ([5], p. 241) regards the empathetic preferences as an important part of morality.

Can empathetic preferences be regarded as being on the same level as Habermas' rational motivation? I think not, for the following reasons:

Upon closer inspection, it becomes clear that empathetic preferences have fewer consequences for their bearers. In Habermas' works, one gets the impression that he already has in mind a rather precise idea how the citizens should act or at least which rules they should adopt. In addition, he shows clear traces of an opposition to approaches that rely on self-interest for their implementation.

This impression does not arise when reading Binmore. First, the empathetic preferences exhibit a peculiar quality: Assuming their existence does not preclude anything for the detailed design of rules and institutions. If A can put herself in B's position, she will in some way try to assess B: On the one hand, if $A$ regards $B$ as rather unreliable or as only interested in short-run gains, she will anticipate B's defection, adapt her own behavior and tend to counter-defect preemptively herself (cf. [9]). If, on the other hand, A regards B as reliable and if there are no contrary incentives for A to defect, A will tend to cooperate. But this is an open-end process the result of which cannot be precluded by the philosopher.

Second, and more important to my mind, the ability to empathize cannot be exploited by other actors. Consider this: If A constrains her behavior in a PD situation, e.g., by subscribing to a rational motivation or a sense of justice, she risks being exploited by $\mathrm{B}$. This can only be avoided if $\mathrm{B}$ constrains his behavior in the same way as A, i.e., by way of sanctions or the like. But if A can just empathize with $B$ in a PD situation, i.e., relies on empathetic preferences, she does not necessarily risk exploitation, especially not in a situation where B acts in ways different from A. To take an example: Suppose that one of the two prisoners in the classic PD situation $(\mathrm{X})$ is motivated by a sense of justice. If the other (Y) knows this but is not motivated in this way himself, he can exploit X without any problem by confessing (i.e. defecting). But if X 'only' has empathetic preferences, this does not necessarily lead to exploitation. It would only mean that $X$ might anticipate the reaction of Y to his own 'moral' behavior. X could, e. g., use this knowledge to try to turn the tables and exploit $Y$. In any case, Y cannot gain any unilateral advantage from knowing that $\mathrm{X}$ has adopted empathetic prefer- 
ences, as $\mathrm{Y}$ would have to count on the fact that $\mathrm{X}$ would anticipate this - by empathizing with $\mathrm{Y}$.

Therefore, the ability to empathize is different from Habermas' rational motivation discussed above. It does not preclude any particular action, and it cannot be exploited. And, what is most important for my argument at hand, it makes the impartiality of communication a strong asset for a society. If this impartiality is endangered or severely restrained, empathizing with one another becomes much more difficult. So there is an argument for promoting the impartiality of communication without relying on more than selfinterest.

\section{CONCLUSION}

I have analyzed some of the ethical background for the GFCC's decision to preliminary stop major parts of the German Law on Data Retention. The decision rests to a great part on the argument that there is such a thing as the impartiality of communication which is indispensable for a society.

This argument seems to have its roots in discourse theory, with its focus on uninhibited communication. I have argued, however, that discourse ethics assumes a rational motivation beyond self-interest, and that it is very doubtful that this rational motivation can remain stable in situations like the prisoners' dilemma.

This does not imply, however, that another theoretical basis of the GFCC's argument could not be found. One can- didate for this basis is Binmore's evolutionary contractarian approach. It does not assume any kind of rational motivation, but just standard self-interest. It however regards the ability to empathize with others as a crucial ability for a society. And thus the impartiality of communication is in fact important and worthy of judicial protection, not only in Germany.

\section{REFERENCES}

[1] BVerfG, 1 BvR 256/08 vom 11.3.2008, Absatz-Nr. (1 - 188), Available from: http://www.bverfg.de/ entscheidungen/ rs20080311_ 1bvr025608.html.

[2] Habermas J. Theorie des kommunikativen Handelns, 2 Bde., Frankfurt/M.: Suhrkamp (engl.: Theory of Communicative Action, Boston 1984) 1981.

[3] Habermas J. Diskursethik: Notizen zu einem Begründungsprogramm. Moralbewußtsein und kommunikatives Handeln, Frankfurt/M.: Suhrkamp 1983; pp. 53-125.

[4] Habermas J. Faktizität und Geltung: Beiträge zur Diskurstheorie des Rechts und des demokratischen Rechtsstaats, Frankfurt/M. (engl:: Between Facts and Norms: Contributions to a Discourse Theory of Law and Democracy, Cambridge, Mass 1996) 1992.

[5] Binmore K. Game Theory and the Social Contract; Playing Fair, Cambridge, Mass., London: MIT Press 1994; vol. 1.

[6] Binmore K. Game Theory and the Social Contract; Just Playing, Cambridge, Mass., London: MIT Press 1998; vol. 2.

[7] Nash J. Equilibrium points in N-person games. Proc Natl Acad Sci USA 1950; 36: 48-9.

[8] Nash J. The bargaining problem. Econometrica 1951; 18: 155-62.

[9] Luetge C. Economic ethics, business ethics, and the idea of mutual advantages, business ethics. Eur Rev 2005; 14(2): 108-18. 